\title{
Hypoparathyroidism, Hypothyroidism and Thrombocytopenia: Rare Constellation of Fahr's Syndrome
}

\author{
Nilma Malik ${ }^{\mathrm{a}, \mathrm{b}}$, Vishwanath Pattan ${ }^{\mathrm{a}}$, Qiang Nai ${ }^{\mathrm{a}}$, Abdalla Yousif ${ }^{\mathrm{a}}$
}

\begin{abstract}
Fahr's syndrome is a rare progressive unremitting neurological disorder, characterized by abnormal bilaterally symmetric brain calcifications. It is associated with various endocrinopathies such as hypothyroidism, hypoparathyroidism and hypocalcemia. This case opens up a new horizon of thought process, as it illustrates the clinical presentation of Fahr's syndrome with thrombocytopenia never reported before. It especially emphasizes on the diagnostic significance of combination of thrombocytopenia with seizures in Fahr's, as this coupling can result in fatal intracranial hemorrhage if timely seizure management is not initiated.
\end{abstract}

Keywords: Hypoparathyroidism; Hypothyroidism; Thrombocytopenia

\section{Introduction}

Fahr's syndrome or bilateral striatopallidodentate calcinosis is a rare progressive neurological disorder which is characterized by abnormal extraosseus calcifications especially involving the brain paranchyema. It has a wide spectrum of clinical presentation but most cases manifest with tetany, seizures, dysarthria, increased intracranial pressure, papilledema, soft tissue calcification, blood dyscrasias, dry hair, alopecia, dental dysplasia, caries and predisposition to Moniliases [1] and extra-pyramidal symptoms.

Prompt recognition of combination of thrombocytopenia with seizures in Fahr's syndrome is crucial as timely treatment can have significant morbidity and mortality benefits.

\footnotetext{
Manuscript accepted for publication June 26, 2014

a Department of Internal Medicine, Raritan Bay Medical Center, 530 New Brunswick Avenue, Perth Amboy, NJ 08861, USA

${ }^{\mathrm{b}}$ Corresponding Author: Nilma Malik, Department of Internal Medicine, Raritan Bay Medical Center, 530 New Brunswick Avenue, Perth Amboy, NJ 08861, USA. Email: nilmamalik1@gmail.com
}

doi: http://dx.doi.org/10.14740/jem228w

\section{Case Report}

A 51-year-old female presented with an episode of tonic clonic seizures preceded by an aura characterized by spasms of her hands. She denied stool or urinary incontinence, post-ictial confusion, fever or headaches. She complained of weakness and tingling in her body, cold intolerance and memory loss. Her family history was significant for intellectual disability in sister. On physical examination, pulse was $88 / \mathrm{min}$, blood pressure was $111 / 76 \mathrm{~mm} \mathrm{Hg}$, RR was $16 / \mathrm{min}$ and $\mathrm{T}$ was $98^{\circ} \mathrm{F}$. Patient was alert but lethargic. There was no thyromegaly or nuchal rigidity. Her deep tendon reflexes showed delayed relaxation phase. Labs were significant for platelets $97,000 / \mu \mathrm{L}$, calcium $0.28 \mathrm{mmol} / \mathrm{L}$, ionized $\mathrm{Ca} 0.59$ $\mathrm{mmol} / \mathrm{L}$, albumin $4.2 \mathrm{~g} / \mathrm{dL}$, phosphorous $6.7 \mathrm{mmol} / \mathrm{L}, \mathrm{Mg}$ $1.4 \mathrm{mg} / \mathrm{L}$, TSH $21.82 \mathrm{ng} / \mathrm{dL}$, UDS negative, and CT of head showed symmetric calcification involving the basal ganglia, corona radiata, centrum semiovale, subcortical white matter and cerebellar hemispheres bilaterally (Fig. 1A, B). Further investigations revealed PTH $3 \mathrm{pg} / \mathrm{mL}$, Vit-D-1,25-OH $21 \mathrm{ng} /$ $\mathrm{mL}$, T3 $64 \mathrm{ng} / \mathrm{dL}$ and T4 $0.63 \mathrm{ng} / \mathrm{dL}$. Urine $\mathrm{Ca}$ and heavy metal screening was negative. Cortisol, Ldh, lactic acid and RPR were normal. Thyroid and parathyroid ultrasonography was normal. Bone imaging revealed marrow calcifications. The patient was diagnosed with Fahr's syndrome and was treated with IV calcium, vitamin D and phosphate binder.

\section{Discussion}

Fahr's syndrome is a rare neurological disorder with a prevalence of $<1 / 1,000,000$ per population [2]. It is most commonly transmitted as an autosomal dominant trait, but may also be passed on as an autosomal recessive trait or occur sporadically. It typically manifests in third to fourth decades of life. It is associated with various endocrinopathies especially hypoparathyroidism. Mutations in SLC20A2, encoding the type II sodium-dependent phosphate transporter 2 (PiT2) is proposed [3]. NaPi-II proteins in the kidney and intestine contribute to hyperphosphatemia by modulating the excretion and absorption of phosphorous [4]. The combina- 


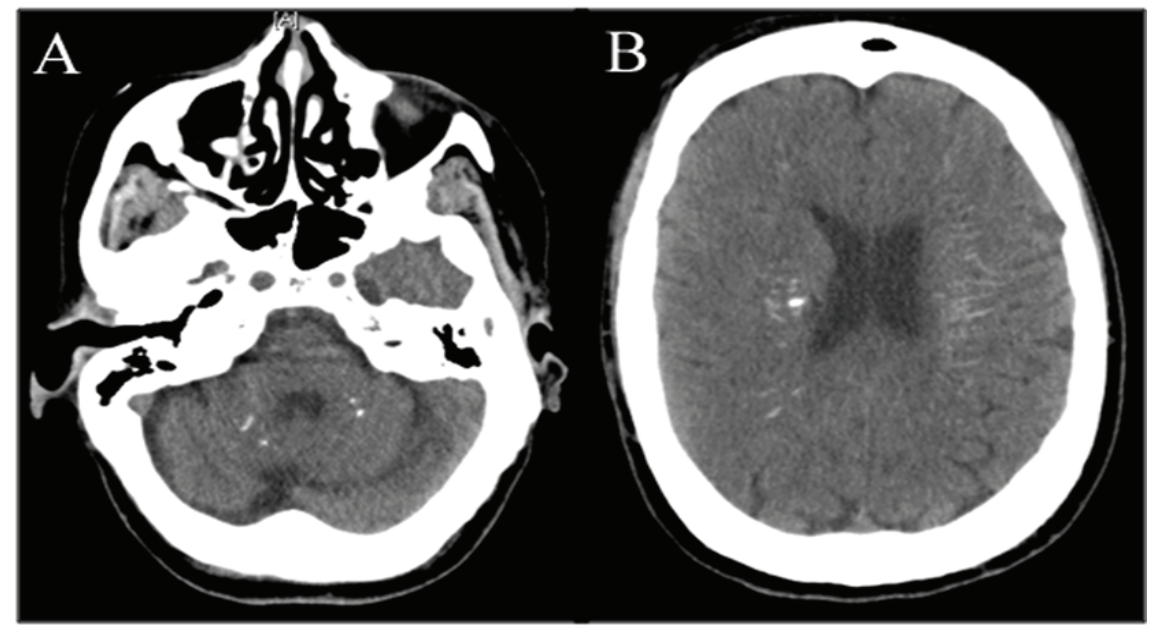

Figure 1. Bilateral calcifications in (A) cerebellum and (B) cerebrum diagnostic of Fahr's syndrome.

tion of hypoparathyroidism, hyperphosphatemia and vitamin D-mediated impaired Ca absorption causes hypocalcemia and disrupted bone homeostasis. This abnormal homeostasis leads to defective iron transport, free radical production and tissue damage leading to extraosseus calcification. Fahr's disease presents clinically with tetany, convulsions, intellectual disabilities, dementia, spastic paralysis, features of Parkinson's disease, choreoathetotic-type movement disturbance $[5,6]$ and abnormal calcification in brain and bone marrow which possibly causes thrombocytopenia, as in our patient. The psychiatric symptoms of Fahr cannot be explained by any other particular disorder of the calcium phosphorus metabolism or any other disease [7]. Pathophysiology of psychosis in Fahr remains unknown, though previous studies have found a decreased cerebral perfusion matching the distribution of calcification in the cortex, which may reflect secondary deficits.

The differential diagnosis of Fahr includes but is not limited to Parkinson's disease, Huntington's disease, progressive supranuclear palsy, Wilson's disease, spasmodic torticollis, oligodendroglioma, lowgrade astrocytoma and arteriovenous malformation. Therefore Fahr's disease is a diagnosis of exclusion $[8,9]$.

There is no cure for Fahr's syndrome, which worsens over time, nor is there a standard course of treatment. The process of calcification cannot be stopped or reversed. Treatment is therefore symptomatic. Prognosis of Fahr's syndrome is variable and often poor.

\section{Conclusion}

It is thus imperative to recognize thrombocytopenia in Fahr's syndrome especially in patients with seizures. Concern arises as in background of pre-existing friable intracranial tissue and seizures this thrombocytopenia may lead to fatal spontaneous intracranial hemorrhage. Therefore appropriate seizure management with close monitoring should be persuaded in these patients.

\section{References}

1. Sobrid SHMJ, Geschwind DH. Familial Idiopathic Basal Ganglia Calcification. GeneReviews. Seattle (WA): University of Washington, Seattle; 2004.

2. Saleem S, Aslam HM, Anwar M, Anwar S, Saleem M, Saleem A, Rehmani MA. Fahr's syndrome: literature review of current evidence. Orphanet J Rare Dis. 2013;8:156.

3. Manyam BV, Walters AS, Narla KR. Bilateral striopallidodentate calcinosis: clinical characteristics of patients seen in a registry. Mov Disord. 2001;16(2):258-264.

4. Werner A, Dehmelt L, Nalbant P. Na+-dependent phosphate cotransporters: the NaPi protein families. J Exp Biol. 1998;201(Pt 23):3135-3142.

5. Cummings JL, Gosenfeld LF, Houlihan JP, McCaffrey T. Neuropsychiatric disturbances associated with idiopathic calcification of the basal ganglia. Biol Psychiatry. 1983;18(5):591-601.

6. Pilleri G. A case of Morbus Fahr (nonarteriosclerotic, idiopathic intracerebral calcification of the blood vessels) in three generations. An clinico-anatomical contribution. (Eng) Psychiatr Neurol (Basel). 1966;152:43-58.

7. Beall SS, Patten BM, Mallette L, Jancovic J. Abnormal systemic metabolism of iron, porphyrin, and calcium in Fahr's syndrome. Ann Neurol. 1989;26:569-575.

8. Fried R. Editorial. Developmental Neuropathology. New York: Springer-Verlag; 1989:541-542.

9. Ang LC, Rozdilsky B, Alport EC, Tchang S. Fahr's disease associated with astrocytic proliferation and astrocytoma. Canada Surg Neurol. 1993;39:365-369. 